\title{
Narrativas e (re)invenções de uma professora em movimento
}

Narratives and (re)invention of a teacher moving

Fabiana Rodrigues de Almeida*

\section{Resumo}

$\mathrm{O}$ artigo consiste em um relato de experiência docente, cujos enfrentamentos didáticos, tão comuns ao universo daqueles que se dedicam à educação, são (re)inventados no encontro entre uma proposta curricular singular para o ensino de História e as dinâmicas próprias de uma sala de aula. A educação para a "sensibilidade histórica", tal como nos propõe Marc Bloch, torna-se o fio condutor capaz de conferir ao docente outra forma de olhar para a aprendizagem de seus estudantes e, a partir dessas demandas, construir repertórios didáticos significativos. Nesse ínterim, podem-se perceber as escolhas e estratégias adotadas por uma professora que se coloca em movimento.

Palavras-chave: currículo; saber docente; aprendizagem histórica.

\section{Abstract}

The article consists in a report of a teacher's knowledge, whose didactic confrontations, so common in among those engaged in education, are (re)invented in a confrontation between a single curricular proposal to History Teaching and the dynamics related to a classroom. The education to "Historic Sensitivity", as Marc Bloch proposes, guides the teachers in another relation with their students and allows the construction of significant didactic directories. In the meantime, we can see the strategic chooses adopted by a teacher that put herself in movement.

Keywords: curriculum; teachers' knowledge; historical learning.

Certa vez, li um texto em que Jorge Larrosa Bondía (2002) abordava o saber de experiência na sua relação com a educação. À primeira vista aquela discussão me pareceu interessante, mas pouco sentido fazia para uma professora que começava a vivenciar os desafios de uma sala de aula. Tempos depois, esse mesmo texto caiu em minhas mãos por acaso, e não por acaso ele tomou novos contornos e produziu em mim reflexões substantivas envolvendo o meu lugar como educadora. Se por um lado o senso comum nos leva a crer que para

\footnotetext{
* Mestre em Educação pela UFJF. fahistojf@yahoo.com.br
} 
ser um bom professor precisamos acumular um vasto cabedal de informações, por outro lado a prática escolar nos apresenta cenários complexos e plurais envolvendo a aprendizagem, de forma que nossos saberes de referência são frequentemente confrontados e destituídos dos seus lugares de certeza. E se para Larrosa "a experiência é o que nos passa, o que nos acontece, o que nos toca” (2002, p.21), é neste lugar de travessia que me encontro: de uma professora e pesquisadora que vê seu campo de conhecimento ser ressignificado no interior da sala de aula e busca, dentro de suas possibilidades, desenvolver repertórios didáticos capazes de contribuir para a formação do pensamento histórico de seus estudantes. Contudo, essa experiência do cotidiano escolar só se transformou em experiência de saber na medida em que o meu mergulho teórico no campo do Ensino de História, desde a graduação e depois no mestrado, se constituiu em uma formação capaz de capturar o humano que há em cenários contingentes da sala de aula e problematizá-los em sua potencialidade educativa. Isso me levou a perceber que a experiência desprovida do lugar teórico não se converte necessariamente em potência reflexiva por parte do professor, e que a formação deve se constituir em um influxo fundamental na vida de todo e qualquer docente, pois é ela quem fornece as ferramentas necessárias de sensibilização do olhar para os processos de aprendizagens.

A experiência docente à qual me refiro neste artigo está vinculada a uma experiência anterior vivenciada por mim enquanto pesquisadora do campo do Ensino de História. Em 2011, a Secretaria Municipal de Educação de Juiz de Fora, cidade localizada no interior de Minas Gerais, decidiu construir para as redes públicas de ensino um currículo específico para cada disciplina escolar, o qual fosse mais condizente com a realidade local. Naquele contexto fui convidada a compor a equipe que pensaria o currículo da área de História, mas aquela discussão se esvaziaria se ignorássemos a natureza política e ideológica que envolve o currículo, pensado na fronteira entre a prescrição e a prática. Talvez tenha sido este o maior desafio na elaboração da proposta curricular: entender a historicidade por trás do currículo.

Ivor Goodson (2007) buscou definir esse componente da cultura escolar como "tradição inventada", termo que tomou emprestado de Eric Hobsbawm e que, de alguma maneira, revela o aspecto de construção intencional do currículo. Seguindo essa linha de raciocínio, os currículos escolares são considerados instrumentos datados, vinculados a um determinado tempo e às demandas sociais 
que envolvem seu contexto de produção. Embora, a priori, a discussão em torno da historicidade do currículo fosse considerada passível de análise pelos professores, sua apropriação ia de encontro a uma forma tradicional de se pensar a educação como um todo, pois a ideia de "tradição" nos remete também as estruturas de saber socialmente postas, e que muitas vezes passam a ser naturalizadas entre os sujeitos, transformando-se em verdades absolutas, orientando suas escolhas, suas ideias e seus modos de agir (Cuesta, 2002).

Assim como em outros campos de saber, o currículo de História também se constitui em uma "tradição inventada", do ponto de vista tanto da sua concepção bem localizada no século XIX, quanto da conversão dessa leitura do passado em verdade histórica, legitimada nas escolas, nas instituições públicas, na indústria cultural e na própria sociedade. Nesse sentido, o currículo de História que inicialmente teria a função de fortalecer os Estados Nacionais Europeus, conferindo à sociedade uma identidade comum capaz de garantir a coesão a partir dos símbolos, língua, heróis e narrativas de um determinado passado de glória, tornou-se ao longo dos séculos seguintes um parâmetro universal, pouco aberto às críticas e às ressignificações.

Essa concepção curricular reverberou nos países do Ocidente colonizados pelos europeus, como o Brasil, os quais passaram a assumir os marcadores de seus colonizadores como próprios de sua cultura. Essa escolha diz de uma decisão política pois, como Marc Ferro (1989) afirma, os valores que definiam uma civilização estavam ancorados em uma perspectiva eurocêntrica, cuja unidade social, centralização, obediência à lei e incorporação de ideais como progresso e democracia forneciam uma espécie de código do direito dos Estados Nações para entrarem na História. Contudo, essa decisão nada inocente de formação histórica se consolidou ao longo dos séculos e ainda hoje, em grande medida, pauta nossa forma de olhar o mundo e nossa própria História. Com certa frequência encontro professores dos anos iniciais preocupados em como ensinar para as crianças o "início" da História do Brasil, com a chegada dos portugueses, de forma lúdica. Porém, sequer existe o questionamento sobre os marcadores de origem dessa narrativa histórica por parte dos docentes. Essa naturalização acerca da narrativa do passado não é exclusiva dos professores dos anos iniciais. Por vezes, conversando com meus colegas professores de História, vejo-os localizar sua especialização ou prática docente dentro dos quatro grandes marcadores temporais europeus, que Jean Chesneaux (1995) 
designou quadripartismo histórico, a saber, História Antiga, Medieval, Moderna e Contemporânea. A maior parte dos professores, sobretudo os que se dedicam a ensinar História Contemporânea, dividem suas angústias quanto a dificuldade em conseguir trabalhar todo o conteúdo prescrito no livro didático. Nesse ínterim, cabem-nos, professores de História, algumas reflexões: será que é possível estudar toda a história da humanidade? Será que a formação histórica pautada na descrição factual do passado é suficientemente capaz de gerar no meu estudante uma aprendizagem histórica significativa? Podem existir caminhos curriculares diferentes para a História?

Essas perguntas se converteram em ponto de partida fundamental para a construção do currículo de História para as escolas municipais de Juiz de Fora. A equipe, formada por pesquisadores do campo do Ensino de História, professores da rede pública e funcionários da Secretaria de Educação, decidiu apostar em uma proposta curricular fechada em três eixos epistemológicos fundamentais para a formação do pensamento histórico do estudante: 1) educar para a compreensão do conhecimento, que consiste em provocar reflexões sobre a escrita da História como forma particular de explicar e conhecer o mundo, ressaltando seu aspecto sempre parcial, seletivo, provisório e relativo quanto à verdade apresentada; 2) educar para a compreensão do tempo implica refleti-lo em sua vasta complexidade, ou seja, desconstruir a ideia de tempo como elemento fixo e supostamente universal. A aprendizagem histórica cujo tempo se coloca linear, cronológico e eurocêntrico deve ser entendido como apenas uma das representações possíveis de narrativas do passado. Outro ponto importante desse eixo recai no trabalho gradativo com as categorias temporais que fundamentam a formação do pensamento histórico, como sucessão, duração, mudança e simultaneidade que permitem aos estudantes estabelecerem deslocamentos temporais e compreenderem contextos de época; 3 ) educar para a compreensão da memória consiste em refletir acerca das operações de lembranças e esquecimentos comuns a todos nós e que conferem sentido ao que somos enquanto indivíduo e sujeito social. As operações de memória estão na base formativa do saber histórico escolar, pois assim como salvamos do esquecimento acontecimentos do nosso passado, a memória histórica também lança mão desse mecanismo, em cada tempo, para legitimar aquilo que deve ser estudado em relação ao vasto passado humano. Desta maneira, é possível 
considerar que em face do que intencionalmente é lembrado ou estudado, muitas outras memórias e temáticas são excluídas de nossos repertórios.

Nessa perspectiva, apresentada por nós à rede pública de Juiz de Fora, as habilidades de pensamento sobrepõem-se à prescrição de conteúdos específicos de uma grande História da humanidade. Isso significa dizer que os conteúdos elencados em sala de aula não constituem um fim em si mesmos, cujos prazos precisam ser vencidos pelos professores e memorizados pelos estudantes, mas tornam-se, no processo educativo, objetos de problematização. Seguimos, portanto, a trilha deixada por Marc Bloch (1997) quanto à defesa de que a base formativa da História não estaria sustentada na erudição histórica, mas na relação entre o procedimento histórico e o saber escolar.

Embora o processo de construção da proposta curricular para as escolas da rede municipal não tenha se dado de forma dissociada da realidade escolar, encontramos grandes restrições por parte do corpo docente. De um modo geral, eles até entendiam e endossavam a importância daquele currículo, mas encontravam enormes dificuldades quanto à sua aplicabilidade em sala de aula e, sobretudo, questionavam a descentralização da informação histórica como elemento norteador do ensino de História. Essa discussão, que já fora levantada por Raimundo Cuesta (2002) em relação à educação na Espanha, também foi criticada por Amézola (2008) ao considerar este o grande dilema do ensino de História hoje na Argentina: enfrentar a esquizofrenia entre o educar para a informação e o educar para o procedimento. De qualquer maneira, a cada etapa de elaboração o currículo era apresentado e debatido com os coordenadores pedagógicos e com os professores que se dedicavam ao trabalho com a História, desde os anos iniciais até os finais do Ensino Fundamental.

No ano seguinte à finalização da proposta curricular, comecei a atuar como professora de História para as turmas do $6^{\circ}$ ano do Ensino Fundamental de uma escola da periferia urbana de Juiz de Fora. E todos os desafios que me foram apresentados pelos professores quanto aos enfrentamentos didáticos do currículo de História agora atravessavam a minha própria prática docente.

Cheguei à escola no início do segundo semestre para substituir uma professora que havia passado em um concurso público. Os estudantes estavam sem aula de História havia pouco mais de 2 meses, e já se haviam acostumado com uma "temporária" grade de horários livres. Ao me apresentar para a coordenadora pedagógica, quis conhecer o projeto político-pedagógico da escola 
para, com base nele, construir um plano de aula. Mas nossa conversa durou pouco tempo, a coordenadora estava muito ocupada e só me entregou o livro didático escolhido pela escola e me direcionou até as turmas do $6^{\circ}$ ano com um sorriso no rosto, por ver que alguns de seus problemas supostamente estariam sanados com a minha presença. Sem nenhum planejamento didático, me vi diante de 18 adolescentes descontentes com o retorno das aulas de História. Meu primeiro movimento com aqueles meninos foi, portanto, buscar entendê-los em sua realidade e captar quais seriam as principais demandas daquele grupo de estudantes. Como ponto de partida para um bate-papo nada pretensioso, disse que não conhecia aquele bairro onde a escola funcionava e fiz estas perguntas: Vocês gostam desse bairro? O que há de melhor aqui? E o que há de pior? Quais lugares vale a pena conhecer? Quais não?

Entre muitas outras perguntas lançadas na roda, a questão da religiosidade bateu forte e gerou posturas exaltadas por parte da turma. Ao falar dos lugares que eu "não deveria conhecer", uma menina me aconselhou não ir ao final da terceira rua, pois ali aconteciam, com frequência, rituais de macumba. Depois de alguns instantes de silêncio, surgiram muitas piadas de intolerância àquele tipo de crença. Alguns meninos lembraram que o livro didático trazia em um dos capítulos a discussão da religiosidade africana por meio dos orixás, e mostraram-se fechados a conhecê-la. Voltei incomodada com tudo o que ouvi de meninos tão jovens sobre o que lhes soava como algo diferente, e vi que era necessário começar pensando esse olhar de alteridade.

Diante do problema da estigmatização do outro, que se coloca como enorme desafio para o ensino de História quanto aos deslocamentos de olhar do estudante para outros modos de vida pautados em diferentes lógicas de pensamento, a escola trazia como única perspectiva plausível e "natural" o cumprimento do livro didático na sua integralidade. Contudo, a potencialidade desse suporte didático só se constitui em caminho possível de diálogo quando o professor se coloca como mediador no processo de aprendizagem, estabelecendo apropriações múltiplas desse material na relação com sua intencionalidade didática.

A pergunta que me fazia naquele momento era: como fazer meus meninos entenderem que a religiosidade africana é uma expressão cultural que merece o mesmo respeito que as demais manifestações de fé? E foi me lembrando das conversas com a turma que encontrei um caminho possível. Eles se mostraram 
fascinados com a mitologia grega, então busquei ali a espinha dorsal para discutir as crenças de matriz africana. Foram necessárias algumas aulas para entenderem o que era mitologia, e montamos um quadro com todas as definições que juntos consideramos fazerem sentido para a turma. O quadro ficou na sala durante meses, pendurado no cantinho da parede. Em seguida, fomos conhecendo várias narrativas mitológicas de diferentes civilizações, sobretudo aquelas que o livro se dedicava a apresentar. Assim passamos pelos egípcios, gregos e romanos e chegamos a alguns reinos da África. Quando os orixás apareceram novamente, estabeleceu-se uma confusão na sala de aula, com opiniões as mais diversas. Propus construirmos um quadro das mitologias estudadas até o momento, de forma que na horizontal estavam as civilizações e, na vertical, suas principais características mitológicas. Com o quadro pronto, lançamos perguntas quanto ao que havia em comum entre as civilizações, no que se refere às suas crenças, e o que havia de diferente. Foi com esse olhar panorâmico que os meninos conseguiram perceber que os orixás poderiam ser compreendidos enquanto cultura de um povo. As piadinhas aos poucos foram substituídas por silêncios e incômodos por parte da turma, o que uma estudante resumiu com muita franqueza: “então, professora, quem tá com a verdade?". Foi com essa pergunta que organizamos a aulas seguintes, que se estenderam até o final do ano.

Não era a primeira vez que o binômio verdade versus mentira aparecia nas aulas de História. Para meus estudantes sempre havia uma verdade em oposição ao que era falso ou incorreto, como se o fato histórico se ancorasse em apenas uma forma de explicação. Mas como sensibilizá-los ao ponto de fazê-los perceber que existem várias narrativas possíveis, e legítimas, envolvendo o mesmo fato? E ainda, que as narrativas estão ancoradas aos lugares de enunciação dos sujeitos? Meu primeiro movimento nessa direção consistia em perceber os limites dessa discussão para os meninos do $6^{\circ}$ ano que, até aquele momento, não consideravam sequer a hipótese de variação dos pontos de vista. Nesse sentido, não adiantava complexificar a reflexão sobre como se constrói o conhecimento histórico, mas introduzir habilidades de pensamento capazes de chamar atenção dos estudantes para os recortes, seleções e intencionalidades que atravessam a escrita da História, e sobretudo fazê-los compreender que por trás de cada narrativa há um sujeito histórico. Como a mitologia tornou-se um conteúdo escolar tacitamente aceito pela turma, optei por mantê-lo como campo de reflexão. 
Quando estava escolhendo sobre quais suportes didáticos iria desenvolver um trabalho com minha turma, lembrei-me de uma das reivindicações levantadas pelos estudantes em um dos meus primeiros dias de aula, e que trazia consigo uma entonação de apelo: "professora, nós nunca vimos filme na escola". Sabia dos desafios de se trabalhar com esse suporte, pois, como Kátia Abud (2003) ressalta, o trabalho com filme em sala de aula exige do professor uma proposta didática bem constituída, já que na maioria das vezes esse suporte não é explorado como elemento de formação. Outro enfrentamento posto para a escolha desse instrumento didático residia na falta de credibilidade quanto à capacidade formativa com que o filme era encarado por aquela comunidade escolar, considerado mero elemento de ilustração. $\mathrm{O}$ estranhamento se tornou ainda maior quando propus associar a exploração didática do filme com um momento de lazer, durante o qual era permitido sentar-se no chão e comer pipoca. Para isso foi necessário convencer a coordenação pedagógica sobre a potencialidade educativa daquela atividade, no que se refere tanto à formação do pensamento histórico do estudante quanto aos laços de humanização que poderiam ser construídos entre a escola e aquele sujeito diante de um evento que poderia criar um universo de empatia e disposição diante do saber. Situações como essas nos revelam que, no âmbito da cultura escolar, o currículo ocupa um lugar de embates e tensões, cuja prática atravessa negociações e consensos que precisam ser frequentemente pactuados entre a comunidade escolar.

Busquei estabelecer um plano de aula no qual o filme saísse do lugar de adereço e se convertesse em fonte de problematização. Levei algumas opções de filmes para votação, e Troia foi o escolhido pela maioria para uma "sessão pipoca”. Contudo, fiz um acordo com a turma: antes de vermos o filme, iríamos conhecer a poesia na qual o roteirista se baseou para produzir aquela narrativa cinematográfica. E assim, lemos adaptações da Ilíada de Homero, cuja síntese dos 24 cânticos populares deu o tom inicial do que poderia ter sido a famosa guerra entre gregos e troianos. Essa leitura ocupou-nos quatro aulas, e nos dirigimos ao filme.

Começamos a ver o filme pelos créditos finais. Lógico que surgiram advertências: "Ih, professora, tá no final”, "volta, tá errado!”, entre outros comentários de estranhamento quanto àquela forma de projeção. Dei um pause no filme e expliquei que começaríamos a assistir Troia a partir daquele ponto, e eles deveriam contar quantas pessoas participaram daquela produção e anotar 
o máximo que conseguissem e em quais setores elas trabalharam. Como a produção de um filme de longa-metragem envolve muitas funções, decidimos nos restringir a apenas quatro delas para compreendermos suas contribuições naquela narrativa. Selecionamos roteirista, cinegrafista, produtor musical e caracterização. Pedi que, na medida do possível, assistíssemos a filme atentos na produção que o envolvia. E assim, em algumas cenas, fazíamos paradas para analisar as escolhas daqueles sujeitos para compor a trama. Buscando torná-las mais palatáveis para a turma, essas paradas eram tratadas como "hora do 'e se'...”, assim, voltávamos a cena e levantávamos questões sobre a produção. Por exemplo, no caso do cinegrafista, "e se..." ele desse um zoom em todas as lutas, teríamos a dimensão da multidão de soldados envolvidos na batalha? Por que ele escolheu esse foco ampliado? Por que em outros momentos reduziu o ângulo de visão? No caso do produtor musical, “e se...” ele optasse por colocar como trilha sonora para o momento em que Aquiles chora a morte do Pátroclo um axé? E se durante as batalhas ouvíssemos músicas suaves de ninar? Como nos sentiríamos diante da cena? Fizemos algumas dessas tentativas em sala, e todos conseguiram perceber que nossas modificações gerariam um outro tipo de filme, com intenções bastante diferentes daquela a que assistíamos naquele momento. A cada exercício imaginativo do "e se" havia uma explosão de reações por parte da turma, com advertências das mais diversas quanto aos nossos critérios de plausibilidade.

Procedimentos pedagógicos aparentemente simples, como a brincadeira do "e se", são capazes de deslocar o olhar do estudante para outras possibilidades de narrativas. No caso, a produção cinematográfica foi problematizada por nós em sala de aula quanto aos seus enfoques, sentidos, texto e estética, conduzindo-nos a perceber que por trás de uma narrativa há um sujeito ou sujeitos que fazem escolhas baseadas em suas intenções. Quando perguntei quais seriam os intuitos de cada produtor em cada cena analisada, a turma conseguiu levantar várias inferências pertinentes, como "ele queria nos fazer chorar", "ele queria mostrar que herói é forte", "as cenas de luta é pra deixar a gente nervoso", entre outras leituras e sensações que possivelmente desejariam provocar no espectador. O fato é que a imaginação pelo "e se" ajudou os meninos a perceberem as intenções por trás de uma produção cinematográfica e, simultaneamente, uma percepção, mesmo que ainda embrionária, de que a 
leitura que se faz do passado está ancorada em uma intenção narrativa do presente.

Ao final do filme, percebi que algumas expectativas haviam sido alcançadas quanto ao procedimento de se perceber a autoria por trás de uma narrativa. Porém, ainda se colocavam como desafios dois pontos principais: a) perceber que os pontos de vista em relação a um acontecimento podem variar em função do lugar que aquele sujeito ocupa na sociedade; b) estabelecer uma conexão mais clara dessa atividade com a escrita da História.

Pensando no primeiro desafio didático a ser enfrentado, propus aos estudantes, como experiência final de trabalho com o filme, uma atividade em grupo na qual cada um deveria assumir o lugar de um dos personagens da trama e recontar a guerra entre gregos e troianos a partir de possíveis emoções, pensamentos e atitudes desse sujeito. Essa atividade gerou um entusiasmo na turma e uma relação saudável com a aprendizagem, que Maria do Céu Pereira (2003) chama de empatia histórica, na medida em que, paralelamente ao conhecimento que a escola oferece aos adolescentes, buscam-se caminhos de significados que lhes permitem criar quadros interpretativos do passado, diminuindo suas estranhezas. Claro que em atividades dessa natureza o professor deve estar atento às chaves de leitura dos estudantes e problematizá-las como fruto de um tempo presente, vivido por eles, no qual cada sujeito irá assumir um lugar narrativo fortemente ancorado em sua experiência social. Contudo, numa perspectiva curricular fechada na descrição de um passado pouco aberto às críticas e ressignificações do presente, essa atividade tornar-se-ia inviável ou, na melhor das hipóteses, iria exigir dos estudantes uma memorização das narrativas apresentadas.

A narrativa criada pelo grupo a partir de uma releitura de Troia poderia se dar em diferentes formas de expressão: música, dramatização, desenhos, poesias... A forma de apresentação era livre. E para minha surpresa a turma se mostrou bastante criativa, seja na escolha de personagens - um grupo resolveu assumir o lugar de um soldado anônimo e conferiu-lhe identidade com nome, profissão, família, características físicas, como foi convocado para a guerra e como vivenciou o conflito - seja nos suportes narrativos utilizados. Esse último, em particular, mexeu comigo profundamente e me fez pensar os desafios didáticos que a escola precisa enfrentar diante de um mundo tecnológico, marcado por nativos digitais que estabelecem outros formatos comunicativos. Um 
dos estudantes que fazia parte dessa turma estava repetindo o $6^{\circ}$ ano pela segunda vez. Quando cheguei à escola, fui informada pelos outros professores sobre a dificuldade de trabalho com ele, cujos limites esbarravam em aspectos cognitivos, já que não sabia ler e escrever, e comportamentais, pois supostamente era desinteressado. No entanto, ele se colocava, na medida do possível, participativo em minhas aulas, e no dia da apresentação do trabalho ele trouxe um pendrive e entrou dizendo se tratar de sua apresentação. Uma vez que ele dizia não ter computador em casa, me assustei, mas logo percebi que ele tivera motivação para ir a uma lan-house, onde produziu sua narrativa. Ao projetarmos seu trabalho no datashow, fui surpreendida com uma animação de 2 minutos extremamente elaborada, na qual ele assumia o lugar de Pátroclo, um dos personagens de Troia, e com uma análise final do que esse sujeito deveria ter pensado ao se fazer passar por Aquiles:

Sacanagem! Já pensou se eu fosse ele? Mas nunca que eu ia pegar as roupas do Aquiles e sair para a guerra. Eu ia ficar quietinho na minha tenda. Eu só ia sair quando o cavalo entrasse em Troia. Mas não tinha como ele saber disso. Mas se eu fosse ele e soubesse do cavalo ia esperar e atacar Troia depois, só cabeça voando, chac, chac, chac...

Confesso que passei a animação duas vezes para apreciarmos juntos os detalhes daquela produção que se colocava para mim como algo extremamente sofisticado, na medida em que aquele jovem dominava uma competência na qual não imagino sequer quais programas e técnicas teriam sido utilizados. Ao se apresentar, ele justificava suas escolhas e como realizou aquela animação. Naquele momento fiquei comovida com a alta capacidade narrativa daquele adolescente que nem de longe se mostrou incapaz ou desinteressado. Luís Fernando Cerri (2011) afirma que hoje a História deve formar o estudante para a competência narrativa, que envolve, em última análise, a apreensão da competência de experiência. Pensando nessa noção dentro do cenário de problematização de um filme em sala de aula, aquele estudante foi capaz de olhar aquela produção na sua qualidade temporal, diferenciando passado, presente e futuro, e percebendo a autoria por trás da narrativa. É fato que ele enfrenta muitas dificuldades quanto ao domínio da linguagem culta, mas consegue interpretar, inferir e se comunicar através das novas tecnologias, da qual é 
tributário. Esse ponto segue para mim, e creio que para a educação como um todo, como reflexão necessária e urgente a ser enfrentada, pois ao final do ano, esse mesmo estudante foi reprovado em várias disciplinas sob as mesmas alegações que me foram passadas quando o conheci.

Após as apresentações de todos os trabalhos, chegava o momento de estabelecermos sínteses sobre a potencialidade pedagógica daquela atividade para o ensino de História. Afinal, encontrava tensões veladas com alguns professores e coordenadores sobre o que tudo aquilo tinha a ver com História. Então, retomei o resumo dos 24 cantos da Ilíada que haviam sido trabalhados em sala de aula e os coloquei dispostos sobre uma enorme linha do tempo que ocupava uma parece inteira da sala de aula, localizando em retrospectiva: $1^{\circ}$ ) o ano de lançamento do filme; $2^{\circ}$ ) a escrita da Ilíada de Homero; $3^{\circ}$ ) o período em que supostamente ocorreu a guerra entre gregos e troianos. Sobre aquela linha fizemos várias perguntas, entre elas: "qual a distância temporal entre o evento e cada uma das narrativas?"; "as pessoas que contaram a história da guerra poderiam estar presentes naquele evento?"; "como eles ficaram sabendo?"; "qual a distância temporal entre a poesia e o filme?”; “o que há em comum entre as narrativas?"; "o que não foi contado no filme?"; "será que Homero também deixou outras narrativas de lado?” etc. Dessa maneira, foi possível problematizar a escrita da História da humanidade, cujos contornos revelam mais esquecimentos, silêncios e lacunas - estabelecidos pelos recortes e possibilidades investigativas daquele que narra - do que sua totalidade.

Claro que problematizações como essas não ocorreram de forma pontual durante aqueles meses com aquela turma, foi um investimento constante, retomado de várias maneiras em cada discussão e atividade em sala de aula. Também não considero que todas as compreensões acerca do pensamento histórico tenham sido alcançadas e vencidas pelos estudantes, mas foi um ponto de partida fundamental para maiores complexificações, que em um trabalho contínuo podem provocar novas maneiras de olhar para o outro quanto aos seus modos de vida e formas de pensar, sendo esse outro alguém próximo ou distante no tempo e no espaço. Edgar Morin (2000) afirma que os saberes necessários à educação do futuro envolvem as dimensões ética e epistemológica, as quais darão autonomia aos sujeitos, visto que o conhecimento passa a ser entendido como processo e não como produto. Nessa perspectiva o filme 
não serviu como suporte de fixação de certezas, mas como produção aberta às criticas, às dúvidas, às hipóteses e às construções de sentido pelos estudantes. Contudo, posso afirmar que essa experiência me reconduziu às reflexões suscitadas pelo currículo da rede municipal de Juiz de Fora quanto à sua pertinência e potencialidade para se pensar a História a partir dos fios teóricos e metodológicos que fundamentam o "educar para a compreensão do conhecimento", "educar para a compreensão do tempo" e "educar para a compreensão da memória". Somente após esse percurso de encontro com o currículo a atividade pedagógica pôde provocar em mim uma experiência de saber, na medida em que me permitiu

parar para pensar, parar para olhar, parar para escutar, pensar mais devagar, olhar mais devagar, e escutar mais devagar; parar para sentir, sentir mais devagar, demorar-se nos detalhes, suspender a opinião, suspender o juízo, suspender a vontade, suspender o automatismo da ação. Cultivar a atenção e a delicadeza, abrir os olhos e os ouvidos, falar sobre o que nos acontece, aprender a lentidão, escutar aos outros, cultivar a arte do encontro, calar muito, ter paciência e dar-se tempo e espaço. (Larrosa, 2002, p.24)

Penso que as construções de repertórios didáticos por parte do docente precisam vir sempre acompanhadas de um olhar sensível para o cotidiano da sala de aula e de perguntas constantes sobre a função formativa do saber escolar, no meu caso, do saber histórico escolar. Seria legítimo, como professora, assumir como caminho de educação um currículo pautado na prescrição de conteúdos canônicos da História dispostos em uma enorme cronologia, mas resolvi enfrentar o desafio de ter o procedimento histórico como chave de leitura para meus estudantes. Isso significa que fiz uma aposta didática, refletida e intencional, nas operações históricas como elementos mobilizadores da aprendizagem histórica.

Retorno a Marc Bloch como fonte de orientação para minha prática docente no sentido de fazer valer uma educação que priorize a "sensibilidade histórica”, cuja ênfase recai na preparação do indivíduo para olhar aquilo que se conhece com os olhos do historiador, ou seja, toda realidade deve ser problematizada e não assumida como dado pronto e acabado. A história como disciplina ensinável serve para conduzir o estudante a problematizar o presente e a se posicionar perante os fatos, compreendendo que os pontos de vista 
variam. Nesse sentido, levá-los a perceber a historicidade presente nas experiências humanas, podendo assim superar uma determinada busca da verdade.

Por fim, considero importante evidenciar que experiências docentes como as que foram aqui narradas estão profundamente vinculadas às práticas de memória que se dão no interior da sala de aula e que por vezes passam por nós de maneira despercebida, mas que em contrapartida permeiam nossos critérios de seleções, nos permitem estabelecer recortes e, sobretudo, tomar decisões quanto ao que deve compor nossos repertórios didáticos e o que pode ser deixado de lado. Em outras palavras, pretendo reforçar que a escola é um lugar fortemente atravessado pelas operações de memória, as quais encontram relevância junto ao saber histórico escolar, pois se configuram como elemento mediador para se pensar os procedimentos históricos capazes de estruturar lógicas de representação do passado, fundamentais para uma aprendizagem histórica de fato significativa.

\section{REFERÊNCIAS}

ABUD, K. M. A construção de uma didática de história: algumas ideias sobre a utilização de filmes no ensino. História, São Paulo, v.22, n.1, p.183-193, 2003.

AMÉZOLA, G. Esquizohistória: la história que se enseña em la escuela, la que preocupa a los historiadores y una renovacion posible de la historia escolar. 1.ed. Buenos Aires: Libros del Zorzal, 2008.

BLOCH, M. Introdução à história. Ed. revista e ampliada por Etienne Bloch. Lisboa: Europa-América, 1997.

BONDÍA, J. L. Nota sobre a experiência e o saber de experiência. Revista Brasileira de Educação, n.19, jan.-abr. 2002.

CERRI, L. F. Ensino de história e consciência histórica: implicações didáticas de uma discussão contemporânea. Rio de Janeiro: Ed. FGV, 2011.

CHESNEAUX, J. Devemos fazer tábula rasa do passado? São Paulo: Ática, 1995.

CUESTA, R. El código disciplinar de la historia escolar en España: algunas ideas para la explicación de la sociogénesis de uma materia de enseñanza. Encounters on Education, v.3, p.27-41, Fall 2002.

FERRO, M. Falsificações da história. Lisboa: Europa-América, s.d.

GOODSON, I. Currículo, teoria e História. 4.ed. Petrópolis, RJ: Vozes, 2001. 
MORIN, E. Os sete saberes necessários à educação do futuro. 2.ed. São Paulo: Cortez, 2000.

PEREIRA, M. do C. M. E. O conhecimento tácito histórico dos adolescentes. Braga: Ed. Universidade de Minho, 2003.

PROPOSTA CURRICULAR da Rede Municipal de Juiz de Fora. Área de História. Juiz de Fora, MG, 2012.

Artigo recebido em 14 de agosto de 2014. Aprovado em 1 de dezembro de 2014. 